\title{
A theoretical and empirical framework for constructing culture-specific stigma instruments for Chile
}

\author{
Uma estrutura teórica e empírica para a construção de \\ instrumentos de estigma específicos para a cultura chilena
}

\author{
Lawrence H. Yang1, Elie Valencia², Ruben Alvarado ${ }^{3}$, Bruce Link4, Nina Huynh', \\ Kristy Nguyen ${ }^{6}$, Kara Morita ${ }^{6}$, Mariella Saavedra ${ }^{7}$, Chak Wong $^{7}$, Sandro Galea ${ }^{8}$, Ezra Susser ${ }^{9}$
}

\begin{abstract}
Different cultural contexts contribute to substantial variation in the stigma faced by people with psychosis globally. We propose a new formulation of how culture affects stigma to create psychometrically-validated tools to assess stigma's culture-specific effects. We propose to construct culture-specific stigma measures for the Chilean context via: 1) open-ended administration of 'universal' stigma scales to a sample of individuals with psychosis, relatives, and community respondents; 2) qualitative analyses to identify how culture shapes stigma and to derive initial 'culture-specific' stigma items; 3 ) construction and pilot-testing of final 'culture-specific' stigma measures; 4) initial psychometric validation among a sample of individuals with psychosis. We identify initial hypotheses for how stigma might threaten the capacities to participate in fundamental activities that 'matter most' in the Chilean context. These include mental illness stigma threatening the man's ability to protect the honor of the family, and the woman's ability to be a 'holy and pure' mother. Mental illness stigma may further endanger the ability of the family to uphold reciprocal obligations within their social network. Developing such measures promises to aid efforts to address culture-specific forms of stigma, and to facilitate implementation of community mental health services, in Chile and other Latin American contexts.
\end{abstract}

Keywords: social stigma; culture; mental health; Latin America.

\section{Resumo}

Diferentes contextos culturais contribuem para a variação substancial do estigma enfrentado por pessoas com psicose globalmente. Nós propomos uma nova formulação de como a cultura afeta o estigma para criar instrumentos validados psicometricamente a fim de avaliar os efeitos específicos do estigma cultural. Propomos a construção de medidas específicas de estigma cultural no contexto chileno através de: 1) administração aberta de escalas "universais" de estigma em uma amostra de indivíduos com psicose, parentes e entrevistados da comunidade; 2) análise qualitativa para identificar as formas de estigma cultural e extrair itens específicos de stigma cultaral; 3) construção e testes-piloto de medidas finais específicos de estigma cultural; 4) validação psicométrica inicial entre uma amostra de indivíduos com psicose. Identificamos hipóteses iniciais de como o estigma pode ameaçar as capacidades de participar em atividades fundamentais mais importantes no contexto chileno. Estes incluem o estigma de a doença mental ameaçar a capacidade do homem para

\footnotetext{
Study carried out at University of Chile - Santiago, Chile.

${ }^{1}$ Assistant Professor at Department of Epidemiology, Columbia University - New York, NY, USA.

2Lecturer at Department of Epidemiology, Columbia University - New York, NY, USA.

${ }^{3}$ Professor at School of Public Health, Faculty of Medicine, University of Chile - Santiago, Chile.

4Professor at Department of Epidemiology and Sociomedical Sciences/ New York State Psychiatric Institute, Columbia University - New York (NY), USA.

${ }^{5} \mathrm{MPH}$ at Department of Epidemiology, Columbia University - New York (NY), USA.

${ }^{6} \mathrm{MA}$ at Department of Psychology, Teacher's College, Columbia University - New York (NY), USA.

${ }^{7} \mathrm{MA}$ student at Department of Psychology, Teacher's College, Columbia University - New York (NY), USA.

${ }^{8}$ Chair and Professor at Department of Epidemiology, Columbia University - New York (NY), USA.

9Professor at Department of Epidemiology, Columbia University \& New York State Psychiatric Institute - New York (NY), USA.

Mailing address: Lawrence H. Yang - Columbia University Mailman School of Public Health, Department of Epidemiology - 722 West 168th Street, Room

1610, New York, NY 10032 USA - E-mail: Ihy2001@columbia.edu

Financial support: none.

Conflict of interest: nothing to declare.
} 
proteger a honra da família, e da capacidade da mulher para ser uma "santa e pura" mãe. O estigma da doença mental pode comprometer ainda mais a capacidade da família para sustentar as obrigações recíprocas dentro de sua rede social. Desenvolvimento de tais medidas promete ajudar os esforços para abordar formas específicas de estigma cultural, e para facilitar a implementação de serviços comunitários de saúde mental, no Chile e em outros contextos latino-americanos.

Palavras-chave: estigma social; cultura; saúde mental; América Latina.

\section{INTRODUCTION}

The implementation of mental health interventions worldwide has been hindered by stigma towards persons who are identified as having a mental disorder and/or who use mental health services ${ }^{1}$. Stigma has been recognized as a fundamental social problem since Goffman's seminal work², which proposed that stigma reduces the affected person "from a whole and usual person to a tainted, discounted one" (p. 3). Whereas culture has been shown to play a key role in determining which characteristics are stigmatized in different groups and at different times ${ }^{3-7}$, these insights have not been fully incorporated into theory and measurement. Nor have effective strategies to decrease stigma been systematically implemented in the delivery of mental health services to consumers ${ }^{8}$. A recently-developed theoretical framework promises to guide investigators in developing culturally-informed measures that allows targeted action to most effectively address this harmful social dynamic ${ }^{9}$. An approach that can be used to assess stigma and its variation across cultures is essential to inform both global and local programs to combat stigma and to promote social integration for people with mental disorders. In Latin America in particular there is little prior work in this area, thus marking it as an important new subject for scientific investigation.

Drawing on concepts from anthropology $y^{9}$ and extensive prior work in stigma, we propose an empirical approach to identify culture-specific stigma barriers in local settings within RedeAmericas that might be applied to low and middle-income contexts both in Latin America and elsewhere. RedeAmericas is a Collaborative Hub for International Research in Mental Health that establishes a research hub in Latin and South America (Chile, Brazil and Argentina). This project proposes a multi-site randomized clinical trial creating a task-shifting intervention involving peer mentors in which primary care is linked to mental health specialty care for individuals with severe mental illness. We propose to construct new measures that can flexibly incorporate the local as well as cross-cultural effects of stigma on people with psychosis within the context of this larger project. We focus on the stigma associated with psychoses, because individuals with psychosis are among the most stigmatized groups, and because RedeAmericas focuses on improving community health care and promoting social integration in this group.

In this paper, we describe a proposed project to develop and validate two stigma measures to assess stigma's universal and cross-cultural manifestations in the Chilean context. However, these methods might be applied to any setting, and may also be generalizable to the assessment of other psychiatric outcomes that may allow similar identification of salient cultural factors. We first discuss the rationale for our approach and new theoretical framework integrating culture and stigma, followed by a description of prior work in this area. We then describe a proposed plan to construct culture-specific stigma measures for the Chilean context. We intend this work to enable identification of salient stigma constructs in other contexts within RedeAmericas, and to ultimately facilitate effective implementation of community mental health in Latin America and in other global settings.

\section{Theoretical stigma frameworks for our approach}

\section{How internalized stigma and experienced discrimination affects individuals}

While stigma has been conceptualized as including mechanisms ranging from internal psychological processes to macro-scale processes on the level of culture and politics ${ }^{8}$, our approach emphasizes the impacts of internalized stigma and experienced discrimination, which have shown substantially negative impacts upon individuals with mental illness ${ }^{10}$. Internalized stigma takes place when stigmatized individuals become aware of mental illness stereotypes and apply these stereotypes to themselves ${ }^{11}$. According to one prominent theory ('Modified Labeling Theory') ${ }^{12}$, people learn about cultural conceptions of mental illness as part of socialization into their culture ${ }^{13-15}$. Individuals form beliefs about whether people will reject a person with mental illness (e.g., as a friend) and devalue such persons (e.g., as less competent). For someone without mental illness, these beliefs have little personal relevance. But for someone who develops a mental illness and is given a psychiatric label he or she may wonder, 'Will others look down on me or reject me because I have been identified as 'mentally ill'?' Expecting rejection, a person might feel badly about themselves or avoid potentially threatening contacts. A substantial literature has shown that labeling-induced stigma predicts: (a) harmful psychological outcomes (lower self-esteem, quality of life, and depression); (b) treatment non-adherence; and (c) constricted social networks ${ }^{10}$. A further consequence is that awareness of negative societal stereotypes may lead to individuals agreeing that 
these stereotypes apply to themselves (i.e., "self-stigma"). Such stigma may also vary with other social factors, such as social class $^{16}$, which may be particularly important in Latin America. Lastly, experienced discrimination - either via individual- or structural-level forms - has further predicted negative psychological and functional outcomes ${ }^{17-18}$. These harmful outcomes are then seen to precipitate vulnerability to symptomatic relapse and to impede social integration and recovery.

\section{Integrating 'culture' into mental illness stigma}

Although modified labeling theory refers to cultural conceptions of mental illness' and core measures of internalized and experienced stigma have shown good psychometric properties across cultures, little effort to culturally tailor either the theory or measures has taken place. This is also true of other stigma approaches. To address this gap, we have advanced a theory emphasizing how cultural-specific constructs and mechanisms determine the most acutely felt effects of stigma. Specifically, we have proposed that culture - which we conceptualize as the interactions that 'matter most' and that define 'full status' within a cultural group ${ }^{19}$ - should be accounted for and measured. To engage in activities that 'matter most' is to certify an individual as having full standing within a cultural group. What is key is that these activities can be empirically identified and operationalized. As a result, we propose that culture affects stigma by threatening an actor's capacity to participate in the activities that determine 'what matters most' (or 'personhood') within a cultural context'.

As one example, because the ability to engage in social exchange networks (or 'face') is an aspect of what is valued most within Chinese cultures ${ }^{20}$, stigma is seen to most powerfully attack one's 'face' and ability to extend one's lineage in these settings. Similar culture-specific effects of stigma have been shown based on 'what matters most', such as 'religious purity' among Muslim group ${ }^{21}$, and the 'Protestant work ethic/economic success' within the US'22. Our current plan capitalizes on this new formulation to identify these culturally-specific stigma dynamics and universal forms of stigma within the Chilean social context (described below). This psychometrically-validated approach, once utilized within Chile, may then be readily implementable across other RedeAmericas sites. This cultural perspective also holds potential as an innovative way of operationalizing culture, not just for stigma, but for other psychosocial variables relevant to psychiatric research that may aid future implementation science.

\section{Prior work in identifying 'what matters most' in relation to stigma}

Highlighting a conceptualization that illustrates the importance of culture in stigma builds upon initial studies in
Chile that indicate feasibility, utility, and the importance of the proposed approach. This conceptual approach to assessing culture-specific stigma builds upon several large epidemiological studies of common mental disorders in Chile ${ }^{23-25}$, and seminal studies of individuals with psychosis, including a needs assessment, assessment of community services, characteristics of untreated psychosis, and training to aid identification of psychosis among primary care physicians ${ }^{26-29}$. These studies form a crucial foundation in order to investigate the impacts that stigma have upon the effective utilization of community mental health services among individuals with psychosis in Chile.

In elucidating a theory that culture can be conceptualized as the core lived engagements that define 'membership' within cultural worlds, Yang et al. ${ }^{9}$ proposed how culture-specific effects of stigma may occur among a distinctive cultural group in the US, specifically, people of Chinese background. Yang \& Kleinman ${ }^{30}$ triangulated across historical texts, ethnographies, and quantitative studies to determine what would 'matter most' to this group and therefore what might be most threatened by the stigma of mental illness. This led to the identification of 'extending one's family lineage and making it prosper' as 'what matters most' within Chinese groups ${ }^{31}$. Yang \& Kleinman ${ }^{30}$ thus proposed that what is threatening to Chinese is how stigma can taint or devastate the future family lineage. Because perpetuation of the family lineage becomes actualized through marriage, Yang et al. operationalized this 'core lived engagement' via the perceived presence of mental illness in a potential marriage partner's ancestry ${ }^{32}$. Empirical testing in a nationally-representative sample ${ }^{32}$ of 56 Chineseand 589 European-American community respondents showed that the Chinese group scored higher on 'family lineage' threat items. Further, this Chinese-specific threat to stigma showed additive power in predicting social distance towards mental illness even after accounting for 'universal' threat processes (i.e., perceptions of controllability and dangerousness).

In addition to using prior empirical work to identify 'what matters most' within a particular cultural group, the identification of target culture-specific stigma constructs may also be revealed through qualitative analyses. To illustrate this approach, Yang et al. ${ }^{33}$ administered the most widelyutilized internalized stigma scale (the Perceived DevaluationDiscrimination Scale ${ }^{12}$ ) in an open-ended fashion to 53 Chinese immigrant individuals with psychosis in New York City and their family members (53 family members; or 106 individuals in total). These audio-taped, open-ended interviews were translated into English. Coders conducted initial content analysis ('open coding') ${ }^{34}$ on identified 'threats to lineage' that classified variations on 'what matters most' in this specific 
immigrant group. Analyses revealed that 'what matters most' was shaped by the specific immigration circumstances encountered. Because this undocumented immigrant subgroup must pay off their smuggling debt ( $\$ 80,000$ US or more) and accumulate financial resources to marry and perpetuate their family line, one main 'threat to lineage' code centered around capacity to gain, and keep, employment. Stigma was thus felt most distinctly in keeping one's psychiatric status secret from employers due to fear of work discrimination. Fear of such stigma led to increased denial of illness and decreased treatment adherence to pursue work opportunities ${ }^{35}$. Similar ethnographic strategies will be employed to identify 'what matters most' in regards to stigma in Chile and to operationalize 'culture-specific' stigma items for this context (described as follows).

\section{Proposed plan to construct culture-specific stigma measures for the Chilean context}

\section{Overview}

As described above, our proposed study is novel in its: (a) use of new theory to gauge culture-specific effects of stigma; (b) blending of ethnographic methods with established psychometric strategies to achieve cross-cultural validation of new measures. Our basic approach will be to first identify culture-specific domains via semi-structured, qualitative interviews and then to construct culture-specific stigma measures derived from this qualitative data. We then test whether these culture-specific stigma items add to the effect of 'universal' stigma items, operationalized by two commonly-used stigma measures, in predicting outcomes. We conceptualize our project as taking place in four steps (Figure 1). Our proposed study in Chile,to develop culturally-specific assessments of stigma builds upon the work already being conducted within RedeAmericas. A central scientific aim of RedeAmericas is to test a randomized clinical trial of "Critical Time InterventionTask Shifting" (CTI-TS) among individuals with psychosis in Latin America. CTI-TS involves the use of Peer Support Workers and one of the goals of the intervention is to change self-perceived stigma. Hence, our innovative means of operationalizing culture in regards to stigma will not only be relevant to the ongoing work in RedeAmericas, but promises to contribute to implementation of locally-specific mental health interventions.

\section{Proposed project}

\section{Sampling and interviewing}

Data will be collected from a sample of individuals with psychosis $(n=20)$, their relatives $(n=15)$, and community respondents ( $n=15 ; n=50$ total). In terms of sampling procedures, both individuals with psychosis and their family members will be ascertained from three psychiatric units located in three general hospitals in the San Joaquin neighborhood of South Santiago, Chile. Hundreds of individuals with psychosis use mental health clinics in San Joaquin regularly. Individuals with psychosis will meet clinic diagnosis of International Classification of Diseases- $10^{36}$ psychotic disorder. The sample will be approximately half male and half female, with the individuals with psychosis and relatives predominantly coming from the same family unit. To sample the community members ${ }^{23-25}$, twenty community members will be randomly selected from households located near those of individuals with psychosis. These individuals will be subsequently approached for interview and will be half male and half female.

To ascertain 'what matters most' among these respondents, two interviewers will administer to all respondents validated, Spanish-versions of Link's 12-item Perceived Devaluation-Discrimination (PDD) Scale ${ }^{12,25}$ and Ritcher's Internalized Stigma of Mental Illness Scale (ISMI) scales ${ }^{37,38}$. From the ISMI, we propose to use the 'Discrimination experience' ( 5 items), 'Alienation' ( 6 items), and 'Social Withdrawal' (6 items) subscales (we exclude the 'Stereotype Endorsement' and the 'Stigma Resistance' ISMI subscales due to redundancy with the PDD scale and low reliability). Because the PDD and ISMI have shown excellent reliability and validity ${ }^{5}$ across cultures, these scales can be utilized to elicit 'cross-cultural' themes of stigma and discrimination.

Open-ended interviewing utilizing these two measures will also be employed to qualitatively elicit key culture-specific domains. Because these scales consist of statements gauging to what extent people with severe mental illness are believed to be devalued by others, feelings of being less than a full member of society, avoidance of social situations, and unfair treatment by others, these questions will be used to elicit 'what is most at stake' in relation to stigma among respondents. Following the approach described above, respondents will be asked in an open-ended manner whether they strongly agree, agree, disagree, or strongly disagree with each statement. Follow-up probes will be used to elucidate stigma domains especially salient to the Chilean setting and to ascertain 'what matters' locally. These stigma domains will then be analyzed qualitatively (see Qualitative analysis section). Interviews will be audiotaped, transcribed into Spanish, and translated into English.

\section{Qualitative analysis to elucidate how culture shapes stigma}

Thematic analyses are proposed to reveal how 'what matters most' shapes the most salient stigma domains across cultures. To establish consensus on initial codes reflecting 'what matters most' (described below) in Chile, an initial 
Step 1:

\section{Administration of 'universal' stigma}

Administration in open-ended fashion to:

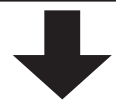

Step 2:

\section{Qualitative analyses}

How culture shapes

- Identification of core 'what matters most' themes

- Derivation of pool of initial 'culture-specific' stigma items from themes

\begin{tabular}{|c|}
\hline Step 3: \\
\hline Administration of initial 'culture-specific modules' to: \\
\hline Local Experts $(\mathrm{n}=5)$ \\
\hline - Construction of final 'culture-specific' measures from interview ratings \\
\hline
\end{tabular}

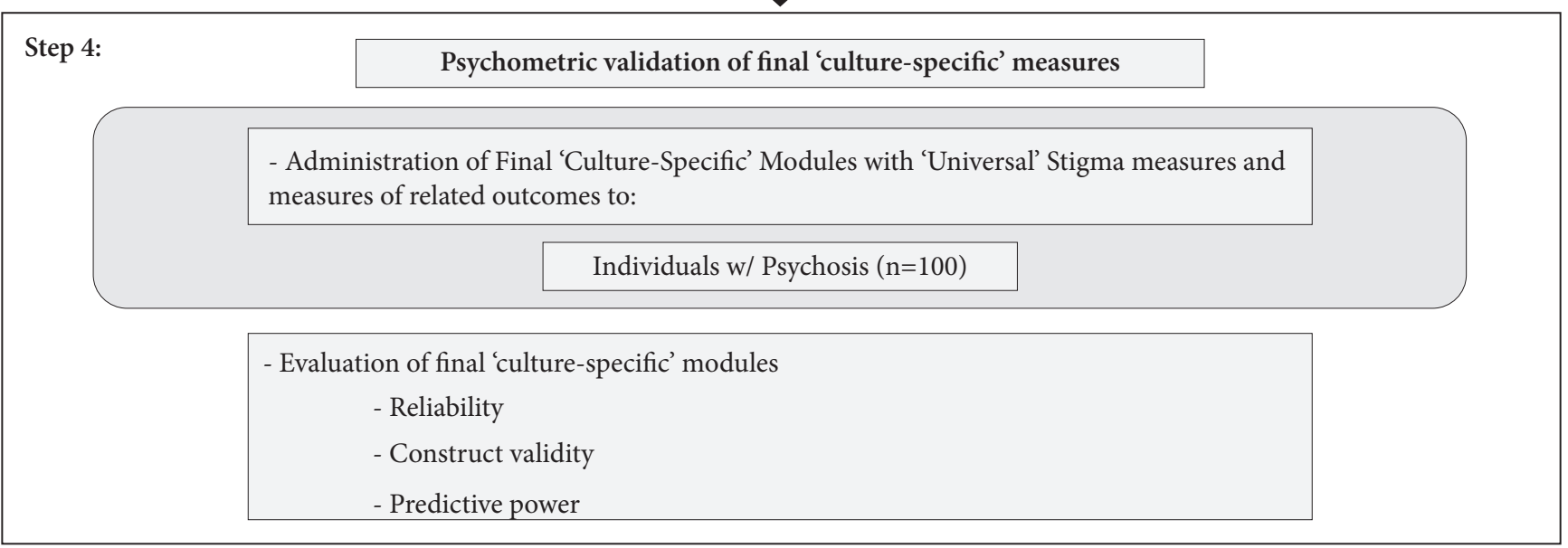

Figure 1. Proposed research project

set of interviews will be coded. Analyses will be facilitated by computer software (ATLAS-TI). While variation exists across cultures, our prior studies have indicated a circumscribed set of codes that capture the main themes of 'what matters most' per stigma construct in a Chinese immigrant group. We thus expect a similar set of organizing codes for each stigma construct of PDD, Alienation, Social Withdrawal, and Discrimination Experiences for the Chilean context. 
Once initial codes are established, the two coders will complete coding on the remaining transcripts, and inter-rater agreement (Kappa) for the code categories will be tracked. To further refine emerging codes, a subset of randomly selected transcripts will be coded from each respondent group. The final, identified core set of themes will then be used to operationalize culturespecific stigma items for further review and testing.

\section{'What matters most' in Chile: Initial formulation}

Prior work describes examples of how everyday engagements over 'what matters most' might be identified in a cultural group ${ }^{39}$. Analyses of historical, philosophical, or religious writings may frame initial hypotheses for the Chilean context. As in other cultures, stigma towards psychosis is viewed as the most severe in Chile ${ }^{40}$. Such stigma is modulated by what has been characterized as a patriarchal structure within the public and private sphere in Chile, which has influenced the gender dynamics manifested within contemporary Chilean society and culture. The influence of patriarchy, as well as the introduction of the Catholic Church by the Spaniards in the 17th century ${ }^{41}$ has profoundly influenced traditional gender roles in Chile. In the private sector, these patriarchal values give rise to how gender roles are created and how they are manifested within the family and in larger Chilean society.

This deep-seated tradition of patriarchy is strongly tied to prescribed gender roles that dictate the dynamic between a man and the other members of the family (wife, mother, children). The man is assigned the role of the patriarch, provider, and protector, known as machismo ${ }^{42}$. Machismo is linked with pride and respect. If a man does not stand up for his or his family's honor, he loses his pride, and the family experiences shame $^{43}$. Catholicism further emphasizes traditional gender roles in Chile by presenting the Virgin Mary as a role model whereby a 'proper' woman is sexually 'pure', and subordinate to her husband and to $\mathrm{God}^{42}$. Tied to 'machismo culture', women's roles are traditionally bound to motherhood, bearing children, and housework. Yet one must be careful not to oversimplify the complex gender dynamics that manifest in Chilean society, as women have simultaneously participated at a high level in the political decision-making process. This dates from the independence of Chile to the present, as the main political parties have demonstrated strong female participation in their leadership structure ${ }^{44}$.

On a sociological level, familial ties in Chile are also considered to be of central importance and typically consist of the immediate family, as well as an extended family consisting of close family friends ${ }^{43}$. Compadrazgo is an associated concept that describes the social institution in Chile consisting of a network of family, friends, classmates and co-workers, and the system of reciprocal moral and social obligations that bind this network together ${ }^{41}$. Compadrazgo helps to extend social networks ${ }^{43}$, which become strengthened when individuals are able to offer and to reciprocally exchange favors. Psychotic illness thus burdens family members who are expected to act as caretakers of the person with mental illness ${ }^{45}$. Family members may therefore act when one family member becomes mentally ill to preserve the ability of the family to uphold social reciprocity within their network and to maintain compadrazgo.

The above analyses suggest initial hypotheses for how stigma might attack the capacities that determine 'what matters most' in the Chilean context. While men who work and provide for their families occupy the dominant position within the family and society, this status becomes threatened by mental illness, which may threaten the man's ability to provide for, protect, and guard the honor of the family ${ }^{43}$. Stigma of mental illness may impact women differently, whose traditional role has been to serve as a 'holy and pure' mother, dedicated to caring for her husband, children, and family ${ }^{46,47}$. Mental illness stigma may further endanger the ability of the family to uphold reciprocal obligations, thus threatening to rupture relationships not only with the specific individual with mental illness, but with that person's entire network. While coding will be focused around these initial themes, 'open coding' will also be undertaken to identify alternate themes by synthesizing related concepts from the text. Triangulation between the three different respondent types will be key to describing shared, essential social interaction. The conditions, interactions, and consequences of these phenomena will be organized to identify how stigma threatens 'what matters most' in the Chilean context, and how variations in 'what matters most' may differentially impact each stigma construct.

\section{Creation of initial 'culture-specific stigma modules' and pilot testing}

We next propose to create two psychometric instruments based on the identified themes. Cultural variation in stigma will be operationalized to create 100 initial 'culture-specific' internalized stigma items for Link's PDD scale, and 50 initial 'culture-specific' stigma items for each of the three ISMI subscales, which will comprise initial 'culture-specific module' pools for each stigma construct. Items will be phrased in an identical fashion as the original scale; e.g., items based on Link's PDD scale will be phrased "Most people in your community would think that people with severe mental illness will [...]". These initial 'culture-specific modules' will reflect the core set of codes that capture 'what matters most' for each stigma domain.

To construct final culture-specific measures, the interviewers will administer the initial cultural-specific 
stigma modules' to five local experts and fifteen individuals with psychosis. 'Cognitive based interviews' ${ }^{38}$ will ask respondents to reflect upon whether an item is salient to 'what matters most' in their local culture. Responses will be elicited regarding how clear an item is and how directly it assesses stigma. A quantitative system ( $1=$ not relevant at all; $5=$ very relevant) will also be used to score item salience. Five local experts in psychosis will be asked to qualitatively and quantitatively judge whether items tap what matters locally. These ratings will be used to select a final 12-item scale (for the PDD scale) and 6-item subscales (for the ISMI) to comprise each scale's 'culturespecific' stigma modules.

\section{Psychometrically validate measures of 'culture-specific' and 'universal' stigma}

To provide initial reliability and validity for our new stigma measures, interviewers will administer the newly developed internalized stigma scales (i.e., the 'culturespecific' modules and the original scales) to a new sample of 100 individuals with psychosis. Only quantitative scores will be recorded. To demonstrate initial reliability, the psychometric properties of the 'culture-specific' modules and the original scales will each be analyzed for internal consistency. Cronbach's Alpha will be anticipated to be greater than 0.7 for each scale, and scales will be examined to see if any item appears to work exceptionally poorly such that it impairs the overall alpha reliability.

To assess initial construct validity of our new 'culturespecific stigma modules', individuals with psychosis will also be given a set of symptom and psychosocial construct measures that show convergent validity (i.e., are moderately correlated either in a positive or negative direction). We first hypothesize that the 'culture specific modules' and the original scales will show convergent validity by correlating with one another in a moderately positively fashion (i.e., $r=0.3-0.5)$. Each stigma scale is also hypothesized to correlate moderately and positively with measures of symptomatology, such as positive symptoms and depressive symptoms. Each stigma scale will also be expected to correlate moderately and negatively with self-esteem, quality of life, and attitudes towards medication treatment adherence. Showing expected and statistically significant relations with other scales in a theoretically-driven fashion would provide initial evidence for construct validity for our 'culture-specific' stigma modules.

As a final step, we propose to examine if our 'culturespecific' modules add predictive value to the 'universal' stigma scales in evaluating associations with related constructs. The same procedure for the PDD scale and each of the three ISMI subscales will be utilized. We will test each set of stigma scales (i.e., each 'culture-specific' module paired with each 'universal' stigma scale) to see how it predicts a core set of related outcomes (e.g., depression, self-esteem, quality of life). For example, we propose to utilize depression as an outcome variable to evaluate added predictive validity from our 'culture-specific' module over and above the 'universal' stigma scale itself. As a first step, the 'universal' stigma scale items (i.e., the PDD or each ISMI subscale) will be assessed as a predictor variable for depression. The corresponding 'culture-specific module' will be assessed next as a predictor variable with the effect of the 'universal' stigma scale items already accounted for. In this case, we hypothesize that the 'culture-specific module' will significantly predict depression even after accounting for the effect of the 'universal' items. A similar procedure will be used to assess the added utility of our 'culture-specific' modules in predicting other outcomes of interest. Patterns in how the newly developed 'culture-specific' module does and does not additively predict related outcomes will be seen as delineating the limits of culture's impacts on stigmarelated outcomes.

\section{CONCLUSION}

Mental illness stigma plays a crucial role in reinforcing the lack of treatment opportunities and social isolation that individuals with psychosis commonly encounter. Furthermore, efforts to develop community mental health services have been hindered by local manifestations of stigma. Yet measuring culture's impact on stigma has not been well defined. A new formulation that stigma attacks 'what matters most' within settings ${ }^{9}$ provides a novel means to operationalize cultural constructs that are likely to influence stigma, and potentially, other significant psychiatric outcomes. We seek to add 'culture-specific' modules to the two most widely used stigma measures that assess internalized stigma and experienced discrimination to capture key, culture-specific aspects of stigma along with its universal forms. Developing cross-cultural stigma measures that can be used in Chile comprises a crucial step towards capturing cultural variation in stigma to maximize interventions at the local level. We aim to encourage future development of culture-specific stigma measures to facilitate addressing critical barriers to the implementation of mental health services in Chile, Latin America, and other global contexts. 


\section{REFERENCES}

1. Thornicroft G, Brohan E, Rose D, Sartorius N, Leese M; INDIGO Study Group. Global pattern of experienced and anticipated discrimination against people with schizophrenia: a cross-sectional survey. Lancet. 2009;373(9661):408-15

2. Goffman E. Stigma: Notes on the Management of Spoiled Identity. New York: Prentice-Hall; 1963

3. Esses VM, Zanna MP. Mood and the expression of ethnic stereotypes. J Pers Soc Psychol. 1995;69:1052-68.

4. Lin MH, Kwan VS, Cheung A, Fiske ST. Stereotype content model explains prejudice for an envied outgroup: Scale of anti-Asian American stereotypes. Pers Soc Psychol Bull. 2005;31(1):34-47.

5. Crandall CS, Martinez R. Culture, ideology, and anti-fat attitudes. Pers Soc Psychol Bull. 1996;22:1165-76.

6. Stangor C, Crandall CS. Threat and the social construction of stigma. In: Hetherton TF, Kleck RE, Hebl MR, Hall JG, editors. The Social Psychology of Stigma. New York: Guilford Press; 2000.

7. Stuber J, Galea S, Link BG. Smoking and the emergence of a stigmatized social status. Soc Sci Med. 2008;67(3):420-30.

8. Yang L, Kleinman A, Cho S. Stigma of Mental Illness. In: Heggenhougen K, Quah S, editors. International Encyclopedia of Public Health. Vol. 6. San Diego: Academic Press; 2008. p. 219-30.

9. Yang LH, Kleinman A, Link BG, Phelan JC, Lee S, Good B. Culture and stigma: adding moral experience to stigma theory. Soc Sci Med. 2007;64(7):1524-35.

10. Livingston JD, Boyd JE. Correlates and consequences of internalized stigma for people living with mental illness: A systematic review and meta-analysis. Soc Sci Med. 2010;71(12):2150-61.

11. Ritsher JB, Phelan JC. Internalized stigma predicts erosion of morale among psychiatric outpatients. Psychiatry Res. 2004;129(3):257-65.

12. Link BG, Cullen F, Struening E, Shrout P, Dohrenwend B. A modified labeling theory approach to mental disorders: an empirical assessment. Am Sociol Rev. 1989;53(3):400-23.

13. Angermeyer MC, Matschinger $\mathrm{H}$. The effect of personal experience with mental illness on the attitude towards individuals suffering from mental disorders. Social Psychiatry Psychiatr Epidemiol. 1996;31(6):321-6.

14. Scheff TJ. Being Mentally Ill: A Sociology Theory. Chicago: Aldine; 1966.

15. Wahl OF. Mental health consumers' experience of stigma. Schizophr Bull. 1999;25(3):467-78.

16. Crocker J, Major B, Steele C. Social stigma. In: Gilbert DT, Fiske ST, Lindzey G, editors. Handbook of social psychology. Boston: McGrawHill: 1998. p. 504-53.

17. Lee S, Chiu MY, Tsang A, Chiu H, Kleinman A. Stigmatizing experience and structural discrimination associated with the treatment of schizophrenia in Hong Kong. Soc Sci Med. 2006;62(7):1685-96.

18. Ertugrul A, Uluğ B. Perception of stigma among patients with schizophrenia. Soc Psychiatry Psychiatr Epidemiol. 2004;39(1):73-7.

19. Kleinman A, Das V, Lock M, editors. Social Suffering. Berkeley: University of California; 1997.
20. Yang LH, Phelan JC, Link BG. Stigma and beliefs of efficacy towards traditional Chinese medicine and Western psychiatric treatment among Chinese-Americans. Cultur Divers Ethnic Minor Psychol. $2008 ; 14(1): 10-8$

21. Lamont M. Responses to racism, health, and social inclusion as a dimension of successful societies. In: Hall PA, Lamont M, editors. Successful societies: how institutions and culture matter for health. London: Cambridge University Press; 2009. p. 151-68.

22. Rüsch N, Corrigan PW, Wassel A, Michaels P, Olschewski M, Wilkniss $\mathrm{S}$, Batia K. Ingroup perception and responses to stigma among persons with mental illness. Acta Psychiatr Scand. 2009;120(4):320-8.

23. Araya R, Lewis G, Rojas G, Fritsch R. Education and income: which is more important for mental health? J Epidemiol Community Health. 2003;57(7):501-5.

24. Araya R, Rojas G, Fritsch R, Acuna J, Lewis G. Common mental disorders in Santiago, Chile: prevalence and socio-demographic correlates. Br J Psychiatry. 2001;178:228-33.

25. Araya R, Rojas G, Fritsch R, Frank R, Lewis G. Inequities in mental health care after health care system reform in Chile. Am J Public Health. 2006;96(1):109-13.

26. Markkula N, Alvarado R, Minoletti A. Adherence to guidelines and treatment compliance in the Chilean national program for first-episode schizophrenia. Psychiatr Serv. 2011;62(12):1463-9.

27. Alvarado R, Minoletti A, Torres-González F, Moreno-Küstner B, Madariaga C, Sepúlveda R. Development of community care for people with schizophrenia in Chile. Accept for publication in International Journal of Mental Health 2012.

28. Alvarado R, Minoletti A, Torres-González F, Moreno-Küstner B, Madariaga C, Sepúlveda R. Informe Final del proyecto "Detección de factores clínicos y sociales que permitan la identificación temprana de personas que presentan un primer episodio de esquizofrenia". Santiago: Ministerio de Salud, 2004.

29. Alvarado R, Minoletti A, Torres-González F, Moreno-Küstner B, Madariaga C, Sepúlveda R. Proyecto del Fondo Nacional de Investigación en Salud: "Evaluación de una intervención comunitaria para la detección precoz y tratamiento oportuno de personas con primer episodio de psicosis". Santiago: Universidad de Chile; 2008.

30. Yang LH, Kleinman A. 'Face' and the embodiment of stigma in China: the cases of schizophrenia and AIDS. Soc Sci Med. 2008;67(3):398-408.

31. WonPat-Borja AJ, Yang LH, Link BG, Phelan JC. Eugenics, genetics, and mental illness stigma in Chinese Americans. Soc Psychiatry Psychiatr Epidemiol. 2012;47(1):145-56.

32. Yang LH, Phelan J, Link B. Cultural Variation and Mental Illness Stigma: A Model Integrating 'Moral Threat'. Submitted to Personality and Social Psychology. In Review.

33. Yang LH, SIa KJ, Lam J, Lam K, Ngo H, Lee S, Kleinman A. Cultural and structural-based stigma among Chinese immigrants with psychosis. In progress.

34. Yang LH, Phillips MR, Lo G, Chou Y, Zhang X, Hopper K. "Excessive thinking" as explanatory model for schizophrenia: impacts on stigma and "moral" status in Mainland China. Schizophr Bull. 2010;36(4):836-45. 
35. Lai G, Lo G, Hong N, Chou Y, Yang L. Migration, Sociocultural Factors, and Local Cultural Worlds among Fuzhounese Chinese Immigrants: Implications for Mental Health Interventions. Submitted to Transcultural Psychiatry. In Press.

36. World Health Organization. The ICD-10 Classification of Mental and Behavioral Disorders - clinical descriptions and diagnostic guidelines. Geneva: WHO; 1992.

37. Ritsher JB, Otilingam PG, Grajales M. Internalized stigma of mental illness: psychometric properties of a new measure. Psychiatry Res. 2003;121(1):31-49.

38. Interian A, Ang A, Gara MA, Link BG, Rodriguez MA, Vega WA. Stigma and depression treatment utilization among Latinos: utility of four stigma measures. Psychiatr Serv. 2010;61(4):373-9.

39. Kleinman A, Hall-Clifford R. Stigma: a social, cultural and moral process. J Epidemiol Community Health. 2009;63(6):418-9.

40. de Toledo Piza Peluso E, Blay SL. Community perception of mental disorders - A systematic review of Latin American and Caribbean studies. Soc Psychiatry Psychiatr Epidemiol. 2004;3(12):955-61.

41. Gomez CF, Rodriguez JK. Four keys to Chilean culture: authoritarianism, legalism, fatalism and compadrazgo. Asian Journal of Latin American Studies. 2006;19(3):43-65.
42. Youssef N. Cultural ideals, feminine behavior, and family control. Comp Stud Soc Hist. 1973;15(3);326-47.

43. Arboleda-Florez J. Mental health in Latin America: Conflict and crisis. Interpsiquis. 2001;2.

44. Franceschet S. The gendered dimensions of rituals, rules and norms in the Chilean congress. The Journal of Legislative Studies. 2010;16(3),394-407.

45. Gutiérrez-Maldonado J, Caqueo-Urízar A. Effectiveness of a psychoeducational intervention for reducing burden in Latin American families of patients with schizophrenia. Qual Life Res. 2007;16(5);739-47.

46. Stewart CL. Chile mental health country profile. Int Rev Psychyatry. 2004;16(1-2):73-82.

47. Binfa L. Chilean women in midlife; aspects on health, sexuality, migration and gender roles: Implications for midwifery. Stockholm: Karolinska Institutet; 2009.

48. Willis GB. Cognitive Interviewing: A tool for improving questionnaire design. Thousand Oaks: Sage Publications; 2005.

Received on: 10/12/2012

Accepted on: 01/27/2013 